\title{
Design para Mudança de Comportamento: Uma Abordagem Interdisciplinar
}

\author{
Design for Behavior Change: A Interdisciplinary Approach
}

ALMEIDA, Henrique Bittencourt; Mestrando; Universidade do Vale do Rio dos Sinos

bittencurt.henrique@gmail.com

SCALETSKY, Celso Carnos; Professor Doutor; Universidade do Vale do Rio dos Sinos

celsocs@unisinos.br

COSTA, Filipe Campelo Xavier da; Professor Doutor; Universidade do Vale do Rio dos Sinos

fcampelo@unisinos.com.br

\section{Resumo}

Desconstruir hábitos e comportamentos que já estão impregnados na rotina das pessoas e transformá-los em algo positivo para elas são tarefas complexas. A percepção da importância dessa problemática fez surgir um campo reconhecido como design para mudança de comportamento "DfBC". Contudo, os estudos realizados nessa temática ainda são recentes e escassos. Assim, identificou-se que as pesquisas até então estabelecidas abordavam brevemente o papel e a participação de todos os atores (designer, usuário e profissionais de outras áreas do conhecimento) no processo de projeto. A partir dessa percepção, foi realizado um workshop com o objetivo de analisar como o designer e os demais atores podem contribuir de maneira interdisciplinar no processo de projeto, na perspectiva do design para a mudança de comportamento. Foi possível observar a importância do desenvolvimento de materiais de apoio que facilitam as relações de trabalho entre designers e não designers.

Palavras Chave: design para mudança de comportamento; codesign; processo de projeto e interdisciplinaridade.

\begin{abstract}
Deconstructing habits and behaviors that are already impregnated in people's routine and turn it into something positive for them are complex tasks. The perception of this problematic's importance had risen a field recognized as design for behavior change "DfBC". However, the studies carried out in this thematic are still recent and scarce. Therefore, it was identified that the research established until then, briefly addressed the role and the participation of all the actors (designer, user and professionals from other knowledge areas) involved in the design process. From this perception on, a workshop was held with the objective of analyzing how the designer and the other actors can contribute in an interdisciplinary way to the project process, into the design perspective for behavior change. It was possible to observe the importance of support materials' development that facilitate the working relationships between designers and non-designers.
\end{abstract}

Keywords: design for behavior change; codesign; project process and interdisciplinarity. 


\section{Introdução}

De acordo com o relatório da comissão pelo fim da obesidade infantil' publicado em 2016 pela Organização Mundial da Saúde (OMS), ao menos 41 milhões de crianças menores de cinco anos são obesas ou apresentam sobrepeso, sendo grande parte desse índice proveniente de países de terceiro mundo e de baixa e média renda. Para Murillo et al. (2016), o aumento ano após ano desses índices demonstra que os meios utilizados atualmente para lidar com essa problemática, apesar de serem relevantes, apresentam um impacto mínimo sobre o comportamento nutricional infantil.

Nesse contexto, abrem-se oportunidades até então pouco exploradas para profissionais desenvolverem projetos que visam estimular hábitos saudáveis. O design é uma abordagem que possui, em seu âmago, a capacidade de transformar contextos sociais e mediar a relação dos seres humanos com os artefatos que os cercam. (FLUSSER, 2007; KRIPPENDORF, 2006). Nessa conjuntura, os artefatos projetados são portadores de significados que podem induzir seus usuários a hábitos e comportamentos. (FOGG, 2009; JELSMA, 2006).

Tendo isso em vista, a partir dos modelos e das bases teóricas da psicologia, economia e neurociência, pesquisadores em design entenderam que é possível projetar com vistas à mudança de comportamento e, a partir dessas perspectivas, começaram a formular suas teorias e seus métodos. De acordo com Niedderer (2014), a percepção dos designers da importância dessas abordagens, fez surgir um campo emergente, que atualmente é reconhecido como design para mudança de comportamento - referenciado a partir de agora pela sigla "DfBC", originada do termo inglês "Design for Behavior Change", área que esse artigo se concentrará.

De acordo com Niedderer (2014) o DfBC possui poucos estudos e só foi reconhecido formalmente como um campo do conhecimento na última década. Por ser uma área emergente, ainda não existe uma definição única para o $\mathrm{DfBC}$, sendo possível, contudo, perceber certa concordância entre alguns dos autores que frequentemente se dedicam a escrever acerca do tema. De forma sintética, estes definem o DfBC como uma abordagem que objetiva influenciar o comportamento dos usuários por meio de projetos de design que buscam incentivar práticas humanas desejáveis. (BOKS, 2011; CASH; GRAM; BOYSEN, 2017; CLUNE, 2010; LILLEY; LOFTHOUSE, 2009; LOCKTON et al. 2013; NIEDDERER, 2013; NIEDDERER et al. 2014; WENDEL, 2014).

Após uma revisão de literatura, identificou-se que as pesquisas até então estabelecidas no DfBC, pouco refletem sobre como os múltiplos atores envolvidos em um projeto para a mudança de comportamento, provenientes de áreas diversas, interagem. Quais seus papéis? Como interferem em processos de conversação e negociação típicos do fazer design. Frequentemente, não são incluídos neste processo todos os atores (designers, usuários e profissionais de outras áreas do conhecimento). A esse respeito, Hermsen et al. (2015) mencionam que os projetos de design para mudança de comportamento estão utilizando as teorias das ciências comportamentais apenas em uma fase preliminar de ideação como fonte de inspiração, o que, por consequência, faz com que, nas etapas seguintes do projeto, essas teorias fiquem perdidas em meio às ideias, aos conceitos e aos outros processos de projeto. Outra problemática levantada por Hermsen et al. (2016) concerne à falta de integração da pesquisa em design com os cientistas comportamentais. Para os autores, ainda não houve muitas tentativas de investigar processos projetuais interdisciplinares no DfBC que envolvam designers, cientistas comportamentais e outros atores.

De acordo com Tromp (2013), o envolvimento de diferentes atores no processo de projeto 
é essencial para completar as necessidades projetuais, podendo gerar soluções com maiores chances de impactar e conduzir a mudança de comportamento. Diante disso, esse artigo tem o objetivo de analisar como o designer e os demais atores podem contribuir de maneira interdisciplinar no processo de projeto, na perspectiva do design para a mudança de comportamento. Para alcançar esse objetivo, foi realizado um primeiro workshop, onde observouse os seguintes itens: (i) como os atores podem ser envolvidos no processo de projeto para a mudança de comportamento, (ii) qual o papel que cada um desses atores desempenha no workshop (iii) como se dá a relação entre os atores.

\section{Design para Mudança de Comportamento}

De acordo com Tromp (2013) e Wendel (2014), as pessoas precisam de estímulos e reforços que as possibilitem a superar as adversidades e as instruam a tomar as decisões que impactem de forma positiva sua vida pessoal e social. A partir da necessidade de compreender como são formadas as atitudes e tomadas de decisão do usuário, designers e pesquisadores procuraram adquirir conhecimento no campo da psicologia para projetar artefatos com maiores chances de promover a mudança de comportamento. Três elementos caracterizam as abordagens DfBC, "a base em teorias comportamentais, o emprego de métodos centrados no usuário e o reconhecimento da responsabilidade ética dos designers no processo de projeto". (MOTA, 2017 p. 37).

Para Niedderer et al. (2014) o DfBC pode ser dividido em quatro áreas-chave: tecnologia persuasiva, o design para o comportamento sustentável, design social e para segurança e, por fim, o design para o bem-estar. A última área-chave que compõe o $\mathrm{DfBC}$, foco deste artigo, corresponde à promoção do bem-estar para o indivíduo e a sociedade. Essa área-chave tem como objetivo desenvolver projetos de design para prevenir ou diminuir as chamadas "doenças do estilo de vida", como obesidade, diabetes, alcoolismo e dependência química. Além da possibilidade de gerar um maior nível de bem-estar para muitas pessoas, os projetos que constituem essa temática podem reduzir as demandas e os custos envolvidos em tratamentos para tais problemas de saúde. (LUDDEN; HEKKERT, 2014; WENDEL, 2014). Em resposta a esse desafio, Ludden e Hekkert (2014) desenvolveram um modelo, denominado Modelo de Design para o Comportamento Saudável (MDCS).

Para a construção do modelo, os autores incorporaram uma teoria da psicologia, conhecida como modelo transteórico de mudança comportamental, desenvolvida por Prochaska, Diclemente e Norcross (1992). Essa teoria demonstra que a construção de um comportamento de longo prazo exige que o indivíduo percorra cinco estágios, os quais compõem o modelo: pré-contemplação, contemplação, preparação, ação e manutenção. Baseados nessa teoria, Ludden e Hekkert (2014) compreenderam que, para projetar artefatos que gerem bem-estar nas pessoas e consequentemente influenciem seus comportamentos, o modelo deveria permitir identificar em qual estágio o indivíduo está localizado no processo de mudança comportamental e, também, o quão motivado ele está para alcançar essa meta. Diante dessas necessidades, os autores associaram 4 estratégias de design aos seis estágios de mudança comportamental do indivíduo: (i) sensibilização - auxilia o usuário a avaliar suas escolhas); (ii) capacitação - fornece condições para o usuário criar seu próprio plano de ação; (iii) manutenção - incentiva o usuário na manutenção desse novo comportamento e, por fim, (iv) intervenção - (Figura 1).

Figura 1 - Modelo de design para o comportamento saudável 


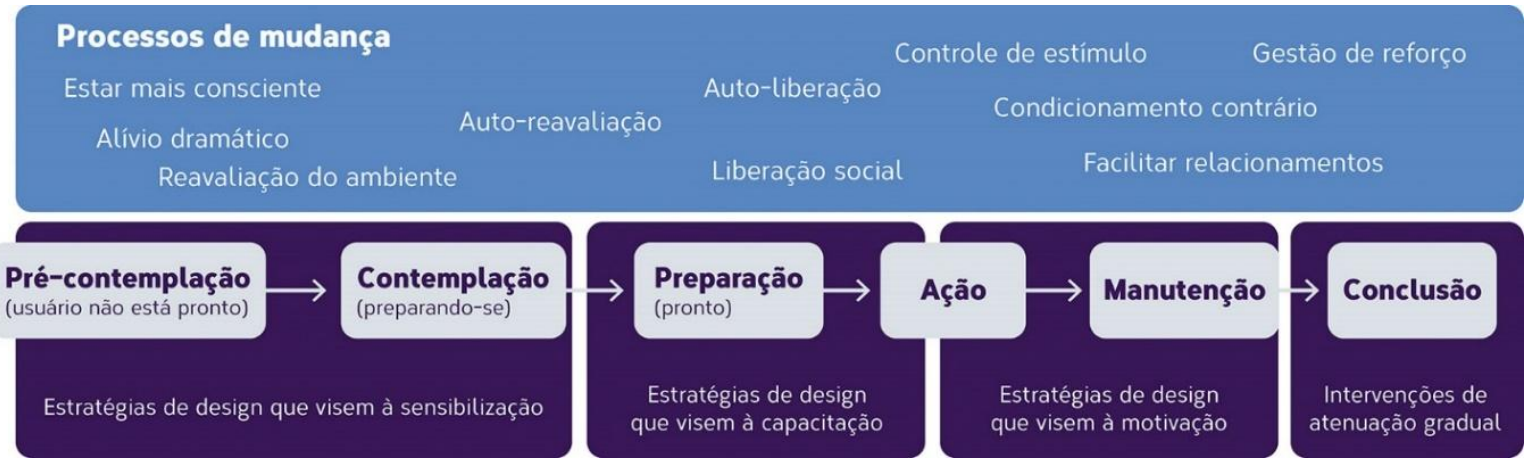

Fonte: adaptado de Ludden e Hekkert (2014).

A primeira das estratégias é a sensibilização, cujo objetivo consiste em auxiliar o usuário a avaliar suas escolhas e os benéficos que esse novo comportamento pode proporcionar. Outra etapa do modelo é a capacitação, cujas estratégias, fornecem condições para o usuário criar seu próprio plano de ação. Já na etapa de manutenção, de acordo com Ludden e Hekkert (2014), ao projetarem artefatos, os designers devem incluir algum dispositivo que ajude o usuário na manutenção desse novo comportamento, auxiliando-o a evitar comportamentos e hábitos antigos. Por fim, na última etapa, em que é utilizada a estratégia de atenuação gradual, o usuário já alcançou seu objetivo; contudo, se não receber algum tipo de reforço, o hábito construído pode deixar de ser executado com o tempo. O objetivo dessa estratégia consiste, assim, em projetar intervenções que reforcem o novo hábito adquirido, visando conceder ao usuário autonomia nesse processo. (LUDDEN; HEKKERT, 2014).

É importante perceber que existe um profundo vínculo entre as palavras estratégia e artefatos. $\mathrm{O}$ artefato, compreendido como algo feito pelo homem com um determinado objetivo busca favorecer a mudança de comportamento pretendido pelas 4 estratégias. Os autores acreditam que a utilização de cada um desses estágios de mudança comportamental no processo de projeto, pode fornecer melhores condições aos designers de criar soluções para o modo como as pessoas se comportam, e não para como elas gostariam de agir. Compreender essa associação é essencial, já que os artefatos projetados para a mudança de comportamento serão utilizados pelos usuários apenas se estes estiverem de acordo com o seu atual estado de motivação no processo de mudança. (LUDDEN; HEKKERT, 2014). A próxima seção se dedica a abordar a participação de outros atores em processos de projeto do design.

\section{Codesign e Interdisciplinaridade}

Conforme comentado, identificou-se nos estudos elaborados sobre o DfBC, a necessidade de aprofundar e desenvolver novas estratégias visando a participação de usuários e atores de outras áreas do conhecimento no processo projetual. Para Tromp (2013) uma abordagem interdisciplinar permite projetar de forma colaborativa intervenções que efetivamente mobilizem as pessoas a adotarem formas de viver mais sustentáveis e positivas para o bem-estar social e individual. (TROMP, 2013).

Buscou-se no conceito de codesign alguns elementos para melhor compreender como outros atores poderiam melhor integrar-se ao processo de projeto. Para Rizzo (2009), o codesign constitui uma forma de colaboração voltada à projetação, em que as atividades se desenrolam de forma completamente transparente e em que todos os participantes envolvidos estão cientes das 
metodologias de projetação e dos objetivos do projeto. Kleinsmann (2008) tem uma visão semelhante e descreve o codesign como um processo em que atores de diferentes áreas compartilham seu conhecimento sobre determinado conteúdo, visando contribuir para o processo projetual. Além de incluir os usuários no processo, o codesign tem como característica a inclusão de especialistas de outros campos do conhecimento. Nesse sentido, Ramaswany e Gouillart (2010) afirmam que a participação de especialistas de diversas áreas do conhecimento pode contribuir no processo de maneira significativa, porém, para que isso ocorra, é necessário que esses atores estejam motivados a participar da atividade.

Quando ocorre a participação de outros atores no processo de projeto, geralmente, empregam-se termos como projeto multidisciplinar, projeto transdisciplinar ou projeto interdisciplinar para caracterizar o processo, o que pode ocasionar, de acordo com Bremner e Rodgers (2013), confusão, uma vez que esses termos não são solidamente definidos na literatura. Diante disso, para o presente estudo, já que se pretende trabalhar com atores de diversas áreas do conhecimento projetando em conjunto com o designer, torna-se necessário compreender os diferentes significados atrelados a esses termos. No que concerne especificamente ao contexto do design, Campos e Chagas (2010) afirmam que a multidisciplinaridade envolve várias disciplinas que tratam do mesmo assunto, sem que ocorra uma interação entre elas. Já a interdisciplinaridade envolve e promove a interação entre essas disciplinas, enquanto que a transdisciplinaridade ultrapassa as disciplinas envolvidas, explorando uma área quase que inexistente.

Com base em tais questões, entende-se que o presente estudo pode ser considerado como interdisciplinar, já que pretende investigar como atores de diferentes áreas do conhecimento podem contribuir no processo de projeto do design para mudança de comportamento. Pelo fato de a interdisciplinaridade ser um caminho composto por elementos diferentes, o diálogo é um fator-chave para que projetos nessa perspectiva sejam bem-sucedidos, pois é um elemento "reflexivo, crítico, entusiástico, que respeita e transforma". (TAVARES, 2008, p. 136), principalmente em trabalhos de equipe. A próxima seção se dedica a trazer o método empregado na realização do workshop.

\section{Método}

Foi realizado um workshop utilizando o modelo de design para o comportamento saudável desenvolvido por Ludden e Hekkert (2014) e também, um conjunto de estratégias elaboradas com base em outros autores que se dedicam a escrever sobre o DfBC. Nessa atividade, objetivou-se observar, entre outras coisas, como se dá a relação interdisciplinar entre os atores envolvidos no projeto e qual é o papel que o designer desempenha nessa relação. É importante esclarecer que este workshop não pretendeu avaliar os resultados que as equipes geraram, mas sim, observar as práticas e relações projetuais que acontecem entre os atores durante o processo projetual.

Para a realização de um workshop, é preciso, antes de tudo, planejar como será o seu processo. A temática a ser discutida no workshop é a da alimentação saudável na infância, com o seguinte desafio: elaborar um jogo ou brinquedo que proporcione a interação positiva entre crianças, pais e alimentos saudáveis, possibilitando assim, a construção ou reforço de um comportamento saudável. O workshop foi composto por um designer, uma psicóloga, uma nutricionista e um usuário (mãe de uma criança entre 3 e 4 anos), com o intuito de estimular relações interdisciplinares entre esses profissionais.

Para auxiliar no processo, foi utilizado o modelo de design para o comportamento 
saudável, elaborado por Ludden e Hekkert (2014). No entanto, esta pesquisa investiga apenas as etapas de sensibilização, capacitação e manutenção. Portanto, a etapa de atenuação de grau não foi utilizada, pois nessa etapa, pressupõe-se que o novo comportamento já esteja assimilado pelo usuário. Deixou-se livre para os participantes desenvolverem um projeto que contemplasse todas as etapas do modelo, ou um projeto para cada uma das etapas.

Baseado nos modelos de Ludden e Hekkert (2014) e Fogg (2003) foram preparados alguns cards de apoio e 3 folhas A3 para serem preenchidas, para cada uma das etapas do modelo de design para o comportamento saudável. Nessas pranchas, também foram incluídos campos em branco, com o título de cada uma das estratégias que Fogg elaborou. Dessa forma, a ideia é que os participantes preencham as estratégias que foram utilizadas, contando o porquê do uso de tais escolhas. Ambos materiais podem ser conferidos na figura 2.

Figura 2 - Materiais elaborados para o workshop

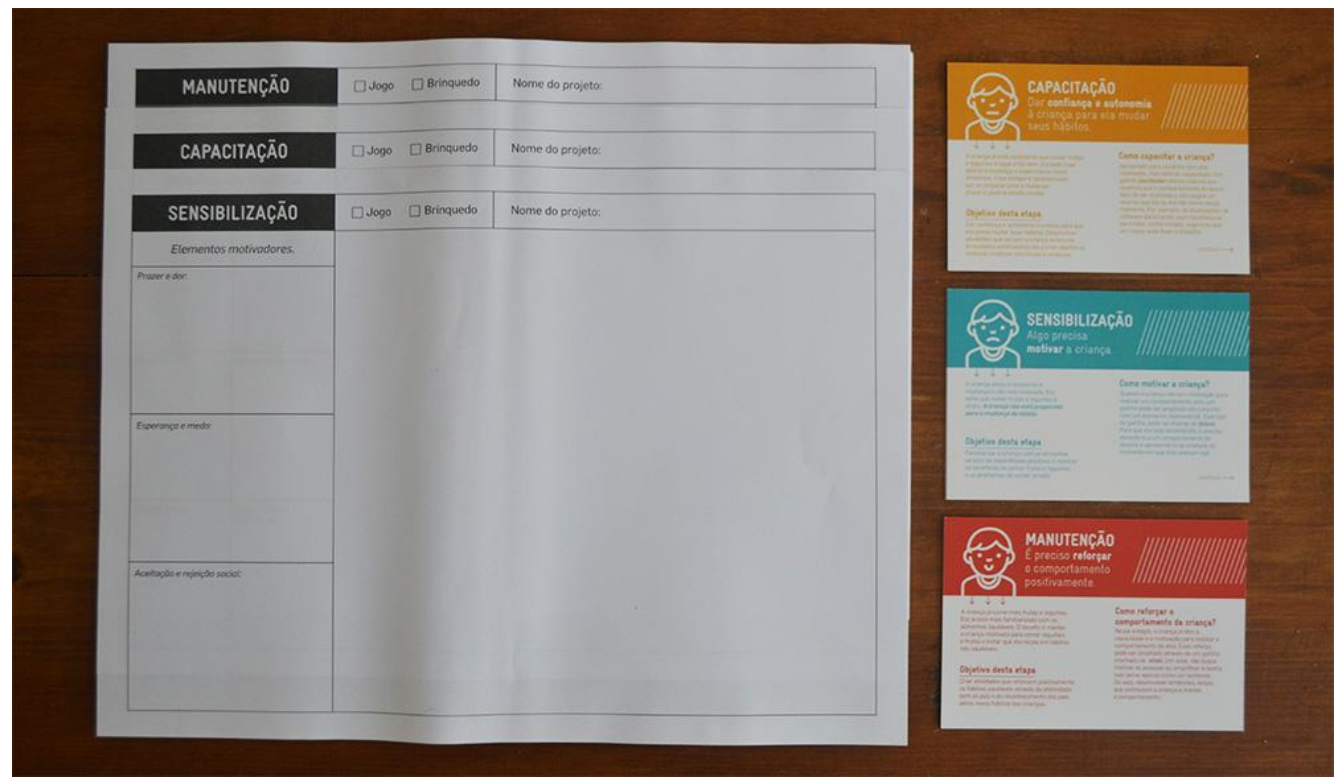

Fonte: elaborado pelo autor.

A dinâmica dos workshops ocorreu da seguinte forma: (i) breve apresentação dos participantes; (ii) apresentação do problema a ser trabalhado; (iii) explicação acerca do modelo e das estratégias projetuais; (iv) entrega dos cards e pranchas; (v) período de projeto em grupo; (vi) apresentação dos conceitos e resultados obtidos; e (vii) entrevista. A seguir, são apresentados os resultados da análise de conteúdo feita a partir da transcrição dos áudios gravados.

\section{Resultados}

O grupo de projeto criou não apenas um jogo ou brinquedo, mas sim um sistema produto serviço que possui uma série de dinâmicas que se modificam ao longo do tempo. O sistema produto serviço desenvolvido, tem como objetivo desenvolver atividades lúdicas que sejam associadas a um universo fantástico, porém esse universo fantástico não deve ser atrelado a algo que já existe, como por exemplo o universo dos super-heróis.

A ideia é que através de histórias a criança aprenda o valor de uma alimentação saudável e em conjunto com os pais, desenvolva as receitas sugeridas pelo serviço. A criança e os pais, 
receberiam um livro de receitas que é associado a um mundo fantástico e, a partir disso, todas as atividades estariam relacionadas a essa temática. Todos os meses de maneira recorrente, um personagem enviaria uma carta e um acessório explicando uma nova receita associada a um ingrediente e ao livro que ela já possui. Por exemplo, o macaco envia uma ou mais receitas relacionadas a banana para a criança. Então naquele mês, a criança descobre junto com os pais todas as qualidades do alimento sugerido pelo animal. Junto com essa carta, também viria um acessório que poderia auxiliar a criança e os pais no desenvolvimento da receita, um exemplo disso, seria um avental com imagens do personagem do mês.

O objetivo dessa atividade, é que com o tempo, a criança reforce o seu comportamento e se aproprie daquele alimento de alguma forma. Para manter sua motivação, existe uma parte do livro onde ela pode responder o que achou da receita e da atividade. Nessa parte, ela poderia fazer um desenho ou pintar alguma figura que o livro possui. Segundo os participantes, a ideia do sistema produto serviço conseguiu contemplar todas as etapas do modelo para o comportamento saudável.

Conforme já mencionado anteriormente, após transcrição das falas, foi feita uma análise de conteúdo. Foram estabelecidas categorias e subcategorias de análise, que se formaram a partir do workshop e entrevistas individuais que ocorreram após a atividade. Para uma melhor compreensão, o quadro abaixo relaciona os conteúdos abordados.

Quadro 1 - Categorias e Subcategorias da análise de conteúdo

\begin{tabular}{|c|c|c|}
\hline Categoria & Descrição & Subcategorias \\
\hline $\begin{array}{l}\text { Dinâmica do } \\
\text { workshop }\end{array}$ & $\begin{array}{l}\text { Refere-se às dinâmicas elaboradas para o } \\
\text { workshop. }\end{array}$ & - \\
\hline \multirow{2}{*}{$\begin{array}{l}\text { Tradução do Modelo } \\
\text { de Design para o } \\
\text { Comportamento } \\
\text { Saudável no projeto }\end{array}$} & \multirow{2}{*}{$\begin{array}{l}\text { Refere-se às estratégias adotadas, o } \\
\text { entendimento e aplicação do Modelo de } \\
\text { Design para o Comportamento Saudável por } \\
\text { parte dos participantes. Além disso, analisa o } \\
\text { resultado do projeto. }\end{array}$} & Estratégias projetuais \\
\hline & & $\begin{array}{l}\text { Uso do Modelo de Design para o } \\
\text { comportamento Saudável }\end{array}$ \\
\hline \multirow[t]{4}{*}{ Atores } & \multirow[t]{4}{*}{$\begin{array}{l}\text { Aborda o papel que cada um dos atores } \\
\text { desempenhou durante o workshop e também, } \\
\text { qual o entendimento que os participantes } \\
\text { tinham uns dos outros antes e depois da } \\
\text { realização do workshop. } \\
\text { Refere-se também ao aprendizado de novos } \\
\text { conhecimentos entre os atores, a condução e } \\
\text { tomada de decisão no processo projetual. }\end{array}$} & $\begin{array}{l}\text { Percepção do papel e da relação } \\
\text { entre dos atores. }\end{array}$ \\
\hline & & Autocrítica dos atores \\
\hline & & Conflitos \\
\hline & & Intercâmbio de conhecimentos \\
\hline
\end{tabular}




\subsection{Dinâmica do Workshop}

Buscou-se identificar se as propostas de atividade influenciaram de maneira positiva ou não o desenvolvimento do projeto. De maneira geral, a dinâmica foi bem recebida pelos participantes, porém algumas sugestões e críticas foram citadas, podendo contribuir para aperfeiçoar as próximas etapas da pesquisa.

Em relação à apresentação feita antes do workshop o designer comenta: "Talvez poderia ter uma etapa, dentro do método quando ele for explicar. Tipo leiam e depois comecem a ter as ideias para fazer o projeto. Seria bom ter um cronograma projetual na própria apresentação". A fala do designer revela que para ele, a apresentação poderia ter um detalhamento em relação ao processo de projeto, definindo micro etapas que auxiliassem na sua condução. Outra sugestão em relação a apresentação, partiu da psicóloga: "Acho que minha sugestão seria mais no sentido de dar exemplos com relação a cada uma das etapas. Tu trouxe um projeto, mas poderia ter mais". Ao apresentar os conceitos que compõem cada uma das três etapas, foi também exibido um projeto, elaborado pelo autor. Esse projeto, trazia um desenho de um brinquedo, que utilizava como base o modelo elaborado por Ludden e Hekkert (2014) e, contemplava duas das três etapas do modelo. Essa sugestão, também partiu do restante dos participantes, exceto pelo designer. Percebe-se então, que o ato de fazer ver, através de um projeto fictício, auxiliou no processo de entendimento das etapas do modelo para alguns atores.

Outra crítica do designer, se manifesta na seguinte fala: "A representação dependia de mim, fica pouco dinâmico para os outros participantes. Talvez ter outros materiais, ter massinha de modelar, ter coisas que os outros participantes possam fazer para representação as ideias". De fato, ao longo do processo projetual quem assumiu a representação das ideias foi o designer, enquanto os outros participantes apenas observavam ou comentavam algo sobre o projeto. Diante disso, percebe-se a necessidade do designer em ter outros materiais ou diretrizes para estimular a ação projetual entre os atores.

\subsection{Tradução do Modelo de Design para o Comportamento Saudável no Projeto}

Essa categoria analisa os materiais distribuídos aos participantes (cards e as pranchas A3) com as estratégias que fornecem suporte teórico aos participantes do workshop. Também, foi analisado o entendimento e aplicação do Modelo de Design para o Comportamento Saudável. O intuito dessa categoria é esclarecer de que maneira os materiais e o modelo contribuíram para os objetivos da pesquisa. Identificou-se duas subcategorias: (i) estratégias projetuais e o (ii) uso do modelo de design para o comportamento saudável.

\subsubsection{Subcategoria: Estratégias Projetuais}

Essa subcategoria objetiva observar como os participantes utilizaram esses conteúdos durante o processo de projeto. O designer, por exemplo, comenta a respeito dos cards distribuídos: "Eles poderiam ser mais visuais, pois tem muito texto, daí tem essa necessidade de todo mundo ter um período para ler e compreender. Talvez seja interessante disponibilizar os cards antes do workshop". Pela fala do designer, percebe-se uma característica comum nesse tipo de profissional, que é a utilização de referências visuais para descrever algum assunto ou tema. Contudo, os outros participantes não relataram nenhum problema em relação a forma como o conteúdo foi disponibilizado. Foi decidido entregar esses materiais apenas no momento da atividade, com o intuito de estimular discussões entre os participantes e também, para observar qual desses atores conduziria o processo de leitura. Esse tipo de observação em relação aos cards, 
se manifesta na fala da nutricionista: "Achei bem explicativo, através dos cards conseguimos sintetizar bem esta questão das etapas que foram apresentadas". Percebe-se aqui, que os cards auxiliaram os participantes principalmente em relação ao modelo de design para o comportamento saudável, pois nos momentos em que algum participante sentia alguma dúvida, os cards eram consultados e a dúvida era resolvida.

Os principais comentários dos participantes nas entrevistas, estão relacionados ao uso das pranchas em folhas A3. A esse respeito, a mãe comenta: "Por mais que eu não tenha desenhado, a inclusão das pranchas ajudaram bastante, pois gente acaba tendo um guia para o trabalho". A fala da mãe revela que a distribuição das pranchas para todos participantes, facilitou no processo de entendimento do projeto entre os atores. Em uma visão semelhante, a nutricionista acrescenta: "Eu vi que o designer virava a folha dele. Depois eu comecei a preencher de maneira organizada, com as ideias que foram surgindo, e aquilo começou a ficar cada vez mais claro". Percebe-se na fala da nutricionista uma vontade em contribuir com a organização do projeto, pois até então, ela não estava entendendo o que o designer estava fazendo nas pranchas. Foi necessário, que ela começasse a preencher as pranchas de uma maneira que ela entendesse, para o projeto começar a ser entendido por ela. Esse fato, deve-se a formas diferentes de trabalho entre os atores. Para o designer, sair desenhando é algo normal, porém, para outros profissionais, talvez a única maneira de colocar as ideias em prática seja anotando as coisas e as organizando.

Ao comentar sobre o uso das pranchas, o designer revela a seguinte posição: "acho que só as pranchas poderiam ser apenas para o designer, porque pelo que deu para ver, as gurias não usaram muito os materiais". Observa-se que o designer não percebeu que as pranchas auxiliaram os demais participantes. Nesse sentido, talvez o designer poderia ter assumido papel de mediador das relações, conforme cita Sanders e Stappers (2008), estimulando o uso em conjunto das pranchas e a partir disso, talvez mudar o resultado do projeto.

Outro aspecto que se revela sobre as pranchas, é que serviram como uma espécie de checklist, como comenta o designer: "Acho que as pranchas funcionaram mais como um checklist, tornando mais seguro o projeto". Em uma visão semelhante, a fala da psicóloga complementa a visão do designer: "O que a gente sentiu, é que a prancha só foi usada depois de ter elaborado mais ou menos a ideia. Elas não serviram para guiar, elas serviram depois só para fazer uma checagem. Elas serviram para aperfeiçoar". Percebe-se na fala de ambos participantes, que as pranchas influenciaram positivamente nos resultados do projeto. Contudo, observou-se que primeiro é feito uma rodada de ideias e somente após isso, é que as pranchas são utilizadas para aperfeiçoar o projeto.

\subsubsection{Subcategoria: Uso do Modelo de Design para o Comportamento Saudável}

Essa categoria analisa o entendimento e aplicação do modelo de design para o comportamento saudável elaborado por Ludden e Hekkert (2014) no workshop. O primeiro aspecto que se revela, é em relação ao processo de projeto. As etapas do modelo não serviram como base para iniciar o processo. Essa observação, se mostra na fala da mãe: "As ideias foram encaixadas em cada uma das etapas ao longo do processo." Ou seja, existia um ciclo de ideias, discussões, rabiscos antes de discutir sobre alguma das três etapas. O designer em uma visão semelhante, complementa a observação anterior: "A gente não criou com uma etapa na cabeça, mas sim criou um produto como um todo, e depois utilizou estas etapas como checklist". Nessa observação, percebe-se mais uma vez que o modelo auxiliou no processo para tornar o projeto 
mais seguro.

Em relação a dificuldade das etapas, percebeu-se que as etapas de sensibilização e capacitação sempre eram as primeiras a serem discutidas. Já a etapa de manutenção, era sempre a última a ser explorada, conforme a fala da mãe: "A etapa mais difícil é a manutenção, pois é preciso sempre reforçar o comportamento". Contudo, observou-se que a etapa de manutenção, foi a que os participantes usaram como insumo antes de ter as ideias e gerar algo visual. Nesse sentido, percebe-se que as etapas de sensibilização e capacitação possuem uma liberdade maior para projetar do que a etapa de manutenção.

\subsection{Atores}

Essa categoria aborda o papel que cada um dos atores desempenhou durante o workshop e também, qual o entendimento que os participantes tinham uns dos outros antes e depois da realização do workshop. Outro elemento que busca-se observar, é o aprendizado de novos conhecimentos entre os atores, a condução e tomada de decisão ao longo processo projetual. Identificou-se duas subcategorias: (i) percepção do papel e da relação entre os atores; (ii) autocrítica dos atores; (iii) conflitos e, por fim, (iv) intercâmbio de conhecimentos.

\subsubsection{Subcategoria: Percepção do Papel e da Relação Entre os Atores}

Essa subcategoria aborda o papel e a percepção que cada um dos participantes teve sobre o outro durante o workshop. Em relação ao designer, percebe-se que o principal papel que esse ator desempenhou, foi o de interpretar as ideias que surgiram ao longo da atividade e representálas através de soluções visuais que auxiliassem os demais atores a compreenderem o projeto, conforme a fala da psicóloga: "O papel dele acho que foi mais na questão de montar concretamente como seria, fazer ver e dar ideias de coisas concretas que poderiam vir, por exemplo a carta ou um avental, a concretude de nossas ideias".

Outros aspectos sobre esse ator se revelarem ao longo do processo. Observou-se que o designer também contribuiu com uma visão estratégica do projeto, buscando sempre transformar as ideias em um sistema produto-serviço ou em um negócio. Essa percepção, se manifesta na fala da mãe, ao ser questionada sobre o papel do designer: "O designer trouxe a gente mais para a realidade comercial do negócio". Essa relação do designer em um papel estratégico, foi compreendido positivamente, porém em alguns momentos os outros atores interpretaram que o designer ao se colocar nesse papel, acaba perdendo um pouco o controle das ideias e do rumo do projeto, conforme a fala da nutricionista: "Na ideia de materializar o nosso jogo, talvez o designer poderia cuidar um pouco para não viajar demais. Acho que alguns momentos ele foi muito além do desenvolvimento do produto". Nessa fala, revela-se a diferente percepção acerca da resolução de um problema projetual. O designer tem como característica em seu processo, um período de geração de alternativas em que são criadas várias opções de soluções. Contudo, esse processo pode ser complexo e desnecessário para profissionais de outras áreas do conhecimento.

Durante as entrevistas, um outro ponto que se revelou é em relação de inibição que um dos participantes sentiu ao ver a o designer desenhando e colocando as ideias no papel. A nutricionista, comenta que no seu consultório sempre tenta se comunicar com as crianças através de desenhos, porém, ao ver o designer em ação, sentiu-se desconfortável ao tentar esboçar algo, conforme a sua fala: "Eu sempre desenho em meu escritório e vim aqui achando que iria fazer algo, porém quando vi o designer desenhando, fiquei com receio de pegar o lápis e desenhar, pois, além dele desenhar bem, os outros participantes também não se arriscaram". Nessa fala, percebe- 
se que além do designer, os outros atores também influenciam a ação projetual, motivando ou desmotivando os participantes.

Percebeu-se também, na fala do designer, que ele gostaria de ter um tempo sozinho para gerar ideias: "Acho que o período de geração de ideias poderia ser mais particular do designer, pois essa primeira etapa seria mais interessante para gerar mais ideias iniciais e tu entender certos aspectos que tu como designer não entende". Essa fala, revela que apesar do processo ser construído em conjunto, às vezes a figura do designer precisa ter a sua individualidade projetual. Dessa maneira, entende-se que nos processos de codesign, o designer às vezes não se sente à vontade em projetar, o que por sua vez, pode alterar os resultados projetuais.

Sobre o papel que a mãe desempenhou, percebe-se que a sua principal contribuição está relacionada a suas experiências práticas de vida como mãe. Na visão do designer, a mãe trouxe elementos que poderiam funcionar na prática, porém em relação a parte criativa do processo, ela foi a participante que menos participou. Outro aspecto que se revelou em relação a participação da mãe, está ligado a sua vontade constante de demonstrar o quanto ela cuida bem de sua filha. Em alguns momentos quando questionada pela nutricionista e psicóloga sobre quais alimentos fornece para sua filha, a mãe acabou se contradizendo. Ou seja, a participação de atores que possuem uma relação de conhecimento sobre alimentação e comportamento, fez com que o projeto, não se deixasse levar pelas opiniões e emoções da mãe. Segundo Sanders e Dandavate (1999) isso acontece em processos de codesign, onde às vezes o usuário informa apenas aquilo que eles querem que os outros participantes escutem.

Em relação a participação da psicóloga, percebeu-se que esse ator desempenhou um papel crucial ao longo da dinâmica. Durante o processo, a psicóloga constantemente utilizou seus conhecimentos sobre a área, para questionar e auxiliar na reformulação das ideias, conforme relata o designer: Em diversos momentos a psicóloga foi uma das mais ativas, ela quem dava sugestões de ideias e logo vinha com uma explanação teórica. Teve uma ideia que surgiu de um insight que a psicóloga teve da própria área". A partir dessa fala, revela-se que ao possuir conhecimentos concretos sobre a mudança de comportamento, a psicóloga tornava o projeto consistente e seguro. Além disso, sempre ao questionar ou validar uma ideia ela fazia uma explanação teórica em que todos os participantes do grupo compreendiam, absorviam e depois já desenvolviam novas ideias em cima da explanação.

Apesar de ser reconhecida como um dos atores com maior participação, para a mãe, o papel da psicóloga não foi crucial: "Não digo que ela foi fundamental, pois todos tiveram um papel importante. Ela começou a falar alguns exemplos que eu já conhecia pela experiência com a minha filha. A gente trocou experiência, porém já eram coisas do dia a dia que eu vivo". Nessa fala, percebe-se que apesar do conhecimento teórico apresentado pela psicóloga aos participantes, a mãe acredita que com a sua experiência, os argumentos teóricos não foram nenhuma novidade, ou seja, a mãe confia mais em suas experiências do que nas explanações teóricas da psicóloga. Nesse sentido, talvez os insumos trazidos pela mãe, não se baseiam nas reais experiências da sua filha, mas sim no seu próprio desejo idealizado.

Já a nutricionista, teve um papel técnico, fornecendo informações específicas sobre a forma como as crianças se alimentam e também em relação ao uso da criatividade na hora de preparar os alimentos. Essas informações foram importantes para a geração de ideias, conforme comenta o designer: "a nutricionista falou que a mão tem os mesmos sensores da boca, então é 
bom a criança nessa idade mexer com o alimento". A partir dessa informação, houve uma rodada de ideias, que após uma tomada de decisão em conjunto, norteou o projeto, conforme fala da própria nutricionista: "Acho que a grande ideia que eu trouxe para o grupo foi a questão do ir para a cozinha, que se desenvolveu a partir daí toda a ideia, tudo o que vai ser, que é o vamos colocar as crianças para cozinhar". Outro aspecto observado no workshop e na entrevista, é com relação a vontade que a nutricionista mostrou em contribuir com o projeto através de outros conhecimentos que ela possuía. Contudo, nenhum dos outros participantes percebeu essa característica e a estimulou a ponto de usar esse conhecimento para o projeto. Talvez para os próximos estudo, seja necessário apresentar alguma ferramenta ou até, deixar um momento específico para que os atores demonstrem suas vontades e habilidades.

\subsubsection{Subcategoria: Autocrítica dos Atores}

Essa subcategoria aborda a autocrítica dos participantes do workshop sobre o resultado do projeto e também sobre a sua atuação. Nesse sentido, todos participantes perceberam que a sua atuação poderia ser diferente ou melhor. A principal autocrítica está relacionada ao tempo, já que quando o workshop foi finalizado havia ainda tempo sobrando para um aprimoramento do projeto, como comenta o designer: "A gente tinha bastante tempo disponível ainda, mas fica uma dinâmica meio chata. A minha apresentação foi só uns rabiscos bem toscos, porque talvez eu precise de mais tempo para fazer essa criação". A partir dessa fala, talvez seja necessário repensar a dinâmica do workshop, promovendo algum tipo atividade que instigue os participantes a utilizarem todo tempo demandado. Contudo, observando por uma diferente perspectiva, percebe-se que talvez o designer pudesse assumir a condução do processo, conforme cita Sanders e Stappers (2008) e, instigar os outros participantes desenvolverem por mais tempo o projeto.

\subsubsection{Subcategoria: Conflitos}

Essa subcategoria refere-se aos conflitos que ocorreram ao longo do workshop entre os participantes. O workshop, transcorreu em uma atmosfera tranquila e descontraída, sem registros de conflitos. Contudo, após as atividades foram realizadas entrevistas onde foi possível perceber alguns conflitos, que no momento da atividade não foram expostos. O designer mostrou um desconforto ao relatar a sua percepção sobre o processo criativo ocorrido em grupo: "Elas não têm a cultura de criação de produto, para nós é muito comum fazer uma variedade de coisas, para nós é muito comum criar um monte de ideias". Nessa fala, percebe-se que o designer ficou um pouco frustrado por o grupo não demonstrar interesse em discutir mais as ideias e gerar outras alternativas de projeto. De encontro a essa fala, na entrevista individual, a nutricionista comenta: "O designer faz muita criação para algo que talvez não seja tão viável fazer. Acho que ele é mais livre na ideia dele. E eu sou um pouco mais centrada". Diante disso, percebe-se que apesar de não ter ocorrido ao longo do workshop um conflito, a fala do designer e da nutricionista, demonstra que ambos se sentiram desconfortáveis em relação ao modelo de trabalho do outro.

\subsubsection{Subcategoria: Intercâmbio de Conhecimentos}

Essa subcategoria aborda como ocorreu a troca de conhecimentos entre os atores e também, como foi o fluxo desse intercâmbio. Como relatado anteriormente, considera-se esse estudo como interdisciplinar, pois envolve profissionais de diferentes áreas, utilizando e compartilhando seus conhecimentos para resolver determinado problema. Nesse sentido, acredita-se que ao longo do workshop ocorreram diversos momentos em que esse compartilhamento de conhecimentos ocorreu. Esse tipo de observação, se revela no comentário 
do designer: "a psicóloga falou que as crianças gostam de coisas mais lúdica, daí a nutricionista falou que a mão tem os mesmos sensores da boca, então é bom a criança nessa idade mexer com o alimento, daí eu já vim com a ideia do livro de receitas". Percebe-se nessa fala que ao compartilharem seus conhecimentos, os atores acabaram impactando uns aos outros, gerando novos conhecimentos ao grupo e por consequência novas ideias para o projeto. Outra questão que se revela, é em relação ao fluxo do processo projeto. Percebeu-se nessa e outras falas da entrevista e workshop, que o fluxo de ideias começava geralmente com a mãe falando sobre a sua filha, após isso a nutricionista e a psicóloga questionavam ou acrescentavam algo relacionado a teoria. Com base nisso, o designer rabiscava algo, gerava ideias, informava ao grupo o que estava desenvolvendo. A partir disso, um novo ciclo de debates e ideias surgiam e o projeto cada vez mais ficava alinhado com o desafio lançado.

\section{Considerações Finais}

A partir do workshop, buscou-se analisar como o designer e os demais atores podem contribuir de maneira interdisciplinar no processo de projeto, na perspectiva do design para a mudança de comportamento. Em relação a dinâmica do workshop, buscou-se fornecer alguns insumos, como os cards e pranchas A3 para promover um maior envolvimento e compreensão acerca da temática por parte dos atores. Percebeu-se que esses materiais auxiliaram no processo e se mostraram uma boa estratégia para tornar o projeto consistente. Contudo, esses materiais não foram suficientes, pois percebeu-se que os atores necessitam de outros insumos para serem se manterem motivados e projetando.

No que se refere às três etapas do modelo de design para o comportamento saudável, pode-se entender que elas auxiliaram os participantes no processo projetual. No entanto, o modelo não serviu como um ponto de partida para os participantes projetarem algo. Os participantes iniciaram o projeto através de conversas, onde cada um apresentava as suas ideias e as discutia e, somente após isso é que essas ideias eram inseridas em alguma etapa do modelo. Para as próximas etapas do estudo, talvez seja interessante apresentar alguma dinâmica que possa auxiliar na geração de ideias, utilizando desde o início o modelo como base.

Como mencionado anteriormente por Hermsen et al. (2016), ainda não houveram muitas tentativas de investigar processos projetuais interdisciplinares no DfBC. Entende-se que a inclusão dos quatro participantes auxiliou no desenvolvimento do projeto. $O$ designer desempenhou algumas funções que já são características da profissão, porém, algumas outras percepções acerca desse ator se revelaram, tais como o seu papel estratégico, o seu caráter inibidor, que por vezes de deixava os outros atores inibidos. Outra característica sobre esse ator em processos colaborativos, é que ele sentiu a necessidade de ter um espaço somente seu para poder gerar outras alternativas e colocar a sua personalidade no projeto. Sobre a mãe, o seu papel foi o dividir as suas experiências como mãe com os outros atores. Sobre a sua participação na geração de ideias, pode-se considerar que ela não teve uma participação ativa como os outros atores. Questiona-se o quanto a presença de especialistas inibem este tipo de participação e o que pode ser feito para vencer esta barreira. Já a psicóloga, foi um ator que influenciou positivamente no processo e resultado do projeto. Esse ator, atuou sempre buscando questionar, compartilhar conhecimentos e gerar ideias. Com a sua participação no processo, os outros atores também se sentiram mais seguros na hora de apresentar o projeto, pois a psicóloga sempre buscou dar-lhes um feedback a respeito de suas ideias. No que se refere a nutricionista, entende-se que seu papel foi importante, pois esse ator forneceu conhecimento técnicos, que geraram insights aos outros 
participantes.

Sobre a relação entre os atores, não houve nenhum conflito e o workshop transcorreu de uma maneira tranquila e descontraída. No entanto, nas entrevistas alguns atores acabaram relatando um desconforto em relação a forma como os outros atores trabalhavam. Diante disso, acredita-se que o presente estudo possibilitou novos conhecimentos acerca da participação de outros atores em projetos do DfBC e também de novos métodos projetuais acerca dessa temática. Contudo, esse estudo ainda não esgotou os temas aqui trabalhados, ao contrário, possibilitaram o surgimento de novas questões a serem exploradas, onde pesquisas relacionadas ao DfBC e a participação de outros atores no processo de projeto podem desenvolver-se a partir do presente estudo.

\section{Referências}

BOKS, C. Design for Sustainable Behaviour Research Challenges. Proceedings of EcoDesign 2011 International Symposium, p. 328-333, 2011.

BREMNER, C.; RODGER, P. Design Without Discipline. Design issues, v.29, n.3, 2013.

CASH, P. J.; GRAM, C. H.; BOYSEN, C. D. Behavioural design: A process for integrating behaviour change and design. Design Studies, v.48, p. 96-128, 2017.

CLUNE, S. Design for Behavioral Change. The Journal of Design strategies, v.4, n. 1, p. 68-75, 2010. FLUSSER, V. 0 mundo codificado. Por uma Filosofia do design e da comunicação (1a ed.) São Paulo: Cosac Naify, 2007.

FOGG, B. J. A Behavior Model for Persuasive Design. In: Proceedings of the 4th international conference on persuasive technology, 2009, Claremont (CA). Anais..., Claremont (CA), ACM, 2009. Art. 40.

HERMSEN, S., MULDER, S., RENES, R.J., \& VAN DER LUGT, R. Using the Persuasive by Design Model to inform the design of complex behaviour change concepts: two case studies. In: Proceedings, 11th Conference of the European Academy of Design. Paris, Université Paris René Descartes, 2015.

HERMSEN, S., VAN DER LUGT., MULDER, S., RENES, R. J. How I learned to appreciate our tame social scientist: experiences in integrating design research and the behavioural sciences. in: $P$. Lloyd \& E. Bohemia, eds., Proceedings of DRS2016: Design + Research + Society - Future-Focused Thinking, v. 4, p. 1375-1389, 2016.

JELSMA, J. Designing 'Moralized' Products: Theory and Practice. In: VERBEEK, P. P.; SLOB, A. (Eds.). User Behavior and Technology Development: Shaping Sustainable Relations Between Consumers and Technologies. Dordrecht, the Netherlands: Springer, p. 221-231, 2006.

KLEINSMANN, J. Barriers and enables for creating shared understanding in co-design projects. Design Studies, v.29, n.4, 2008.

KRIPPENDORFF, K. The semantic turn. A new foundation for design. Boca-Raton: Taylor \& Francis, 2006.

LILLEY, D.; LOFTHOUSE, V. Teaching Ethics For Design For Sustainable Behaviour: A pilot study. Design and Technology Education: An International Journal. v.15, n.2: 55-68, 2009. 
LOCKTON, D.; HARRISON, D.; STANTON, N. Exploring Design Patterns for Sustainable Behaviour. The Design Journal, London, v.16, n. 4, p. 431-459, 2013.

LUDDEN, G.; HEKKERT, P. Design for healthy behavior design interventions and stages of change. Proceedings of the Colors of Care: The 9th International Conference on Design \& Emotion. Ediciones Uniandes, Bogotá, p. 482-488, 2014.

MOTA, J. G. O processo de design para mudança de comportamento orientado à alimentação saudável infantil. 2017. 178 f. (Dissertação) - Mestrado em Design Estratégico, Universidade do Vale dos Sinos - UNISINOS, Rio Grande do Sul, 2017.

NIEDDERER, K. Mindful Design as a Driver for Social Behaviour Change. Consilence and Innovation in Design - Proceedings and Program, 2013.

NIEDDERER, K., MACKRILL, J., CLUNE, S., LOCKTON, D., LUDDEN, G., MORRIS, A., CAIN, R., GARDINER, E., GUTTERIDGE, R., EVANS, M., HEKKERT, P. Creating Sustainable Innovation through Design for Behaviour Change: Full Report. University of Wolverhampton, Project Partners \& AHRC, 2014.

RAMASWANY, V.; GOUILLART, F. The power of Co-creation: Build it with them to boost growth, Productivy and Profits, 2010.

RIZZO, F. Strategie di co-design: Teorie, metodi e strumenti per progettare com gli utenti. Milão: Franco Angeli, 2009.

SANDERS, E. B. N.; STAPPERS, P. J. Co-creation and the new landscapes of design. CoDesign, [S.I.], v.4, n. 1, p. 5-18, Mar. 2008.

TAVARES, D. E. A interdisciplinaridade na contemporaneidade: qual o sentido? In: FAZENDA, I. C. A. (Orgs.). O que é interdisciplinaridade? São Paulo: Cortez, p. 135-146, 2008.

TROMP, N. Social Design: How products and services can help us act in ways that benefit society, Ph.D.thesis, Delft University of Technology, 2013.

WENDEL, S. Designing for Behavior Change. O’Reilly Media, Inc., 2014. 